\title{
Editorial
}

\section{Variable Structure Control and Applications}

\author{
Yuqiang Wu, ${ }^{1}$ Xinghuo Yu, ${ }^{2}$ Lijun Zhang, ${ }^{3}$ Yu Kang, ${ }^{4}$ and Ningsu Luo ${ }^{5}$ \\ ${ }^{1}$ Research Institute of Automation, Qufu Normal University, Qufu, Shandong 273165, China \\ ${ }^{2}$ Platform Technologies Research Institute, RMIT University, GP.O. Box 2476, Melbourne VIC 3001, Australia \\ ${ }^{3}$ School of Marine Technology, Northwestern Polytechnical University, Xian, Shanxi 710072, China \\ ${ }^{4}$ Department of Automation, University of Science and Technology of China, Hefei, Anhui 230007, China \\ ${ }^{5}$ Department of Electrical Engineering, Electronics and Automatic Control, Institute of Informatics and Applications, \\ University of Girona, Girona, Spain
}

Correspondence should be addressed to Yuqiang Wu; yu_qiang_wu@126.com

Received 4 September 2013; Accepted 4 September 2013

Copyright (C) 2013 Yuqiang Wu et al. This is an open access article distributed under the Creative Commons Attribution License, which permits unrestricted use, distribution, and reproduction in any medium, provided the original work is properly cited.

Variable structure control (VSC) has been recognized as a powerful theoretical methodology in applications of the practical control engineering, especially in the sliding mode. The system is with complete insensitivity to the system variations, which satisfies certain matching conditions. In last decades, the ideas of the VSC and switching control are successfully applied to the practical industrial systems, for example, motor (or force/torque) control in mobile robots, electric drives, rigid spacecrafts, underwater ships, and many other mechanical systems. More recently, by combining with other control methods, the discontinuous controller in VSC is widely used in many practical applications and theoretical analyses.

This special issue has given some aspects of the art in theoretical developments and industrial applications of variable structure systems (VSSs) and sliding mode control. It contains fifteen papers; among them, three are concerned with the robust analysis of the uncertain systems by sliding mode control. " $H_{\infty}$ observer-based sliding mode control for uncertain stochastic systems with time varying delays" by $\mathrm{P}$. Zhang et al. is concerned with sliding mode control for uncertain time-delay systems subjected to input nonlinearity and stochastic perturbations. "Sliding mode control design for a class of SISO systems with uncertain sliding surface" by G. Wang et al. studied the sliding mode controller with uncertain sliding surface. An adaptive sliding mode controller, strongly robust to exotic perturbations, is designed in "Robust adaptive sliding mode control for generalized function projective synchronization of different chaotic systems with unknown parameters" by X. Li et al.

Two papers solve the controller design and the stabilization for the nonholonomic systems with nonlinear uncertainties. "Adaptive sliding mode control of uncertain high-order nonholonomic systems with unknown control coefficients" by Y. Zhao investigated the global stabilization problem and proposed an adaptive sliding mode control (SMC) law based on a constructive manipulation by adding a power integrator technique. The finite-time tracking control for nonholonomic mechanical systems with affine constraints is discussed in "Adaptive sliding-mode tracking control for a class of nonholonomic mechanical systems" by W. Sun.

Seven papers are related to the aspects of the practical applications in the motors control and near space vehicles and tracking control of spacecraft by using variable structure control. "Decomposed sliding mode control of the drive with interior permanent magnet synchronous motor and flexible coupling" by J. Vittek and S. Ryvkin exploited principles of vector control to divide motor into channels for control of magnetic flux and control of torque separately, and the sliding mode control keeps demanded value of magnetic flux and load angle in the presence of vibration modes and external disturbances. "Finite-time integral sliding mode control for motion control of permanent-magnet linear motors" by X. Mo and Q. Lan proposed a finite-time control law and a saturation function based on finite-time integral sliding mode technique such that the PMLM can track the desired 
trajectory in the presence of disturbances. "Super-twisting algorithm second-order sliding mode control for a synchronous reluctance motor speed drive" by W.-B. Lin and H.-K. Chiang utilized the second-order sliding mode controller to a synchronous reluctance motor system and proposed a control scheme based on super-twisting algorithm. "A design method for fault reconfiguration and fault-tolerant control of a servo motor" by $\mathrm{J}$. He and $\mathrm{C}$. Zhang designed a sliding mode observer to achieve fault reconfiguration based on the equivalence principle. "Sliding mode control for a class of uncertain MIMO nonlinear systems with application to near-space vehicles" by $\mathrm{M}$. Chen et al. presented the robust sliding mode control to track the desired system output in the presence of the unknown system uncertainty and external disturbance and the backlash-like hysteresis and applied it to the attitude control of near space vehicle. "Finitetime second-order sliding mode controllers for spacecraft attitude tracking" by C. Pukdeboon considered the attitude tracking control problem of a spacecraft nonlinear system with external disturbances and inertia uncertainties based on finite-time second-order sliding mode control schemes. By the use of port-controlled Hamiltonian and finite-time sliding mode control scheme the speed regulation of permanent magnet synchronous motor is investigated in "Continuous finite-time terminal sliding mode IDA-PBC design for PMSM with the port-controlled Hamiltonian model" by $\mathrm{S}$. Yu et al.

There are two papers that discuss the switching control method and the switched system. "Multiple model adaptive nonlinear observer of dynamic positioning ship" by Y. Xie et al. considers the filtering problem of dynamic positioning ship for the slowly-varying sea state and a multiple model adaptive observer (MMAO) for dynamic positioning ship is presented. In " $H_{\infty}$ Control for stochastic systems with Markovian switching and time-varying delay via sliding mode design" by $\mathrm{L}$. Gao and $\mathrm{Y}$. Wu, an integral sliding surface corresponding to every mode is constructed, and the given sliding mode controller concerning the transition rates of modes can deal with the effect of markovian switching.

Finally, a discrete-time chattering free sliding mode control and its application was studied in "A discrete-time chattering free sliding mode control with multirate sampling method for flight simulator" by Y. Wu et al. It improved the tracking accuracy of flight simulator and expended its frequency response by constructing the multirate sampling sliding mode controller.

Although variable structure control theory, especially the discontinuous control method, is not a new topic, the applications in control theory of nonlinear systems and the aspects in practical applications are yet to receive more and more attention, and there still exist many challenging problem, and research interests. It is noted obviously that both the new variable structure control theory and all the feasible applications of systems by sliding mode control could not be possibly covered in this special issue. Especially, there are many advanced variable structure control schemes that have developed in the last few years and are mentioned in recent published journals. We have made our best effort to discuss the advances of VSC in both theories and applications and believe that the aforementioned papers in this special issue improve our understanding of VSC in many aspects.

\section{Acknowledgments}

We would like to take this chance to express our deep gratitude to the authors for their excellent contributions and to the all of reviewers and our colleagues who have contributed directly or indirectly to this special issue. Yuqiang Wu
Xinghuo Yu
Lijun Zhang
Yu Kang
Ningsu Luo 




Advances in

Operations Research

mansans

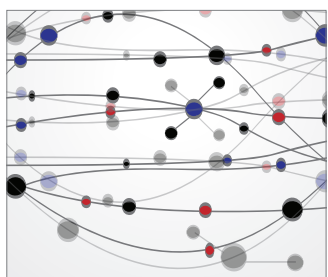

The Scientific World Journal
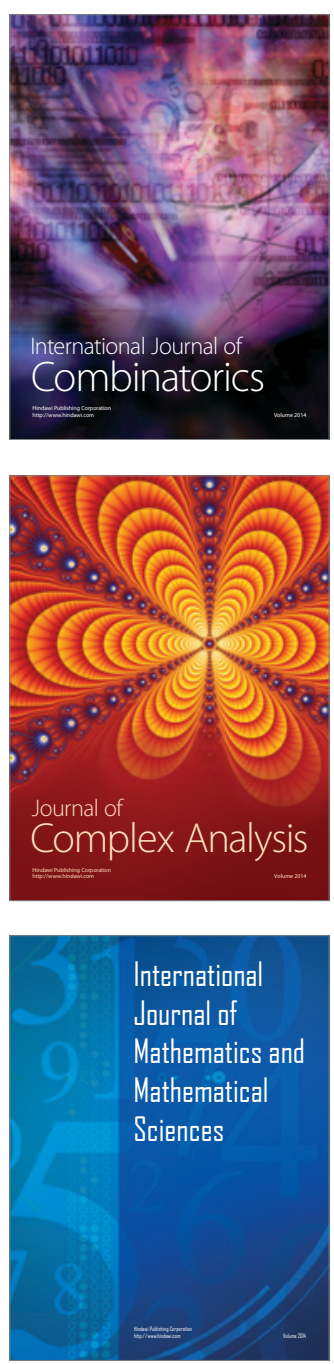
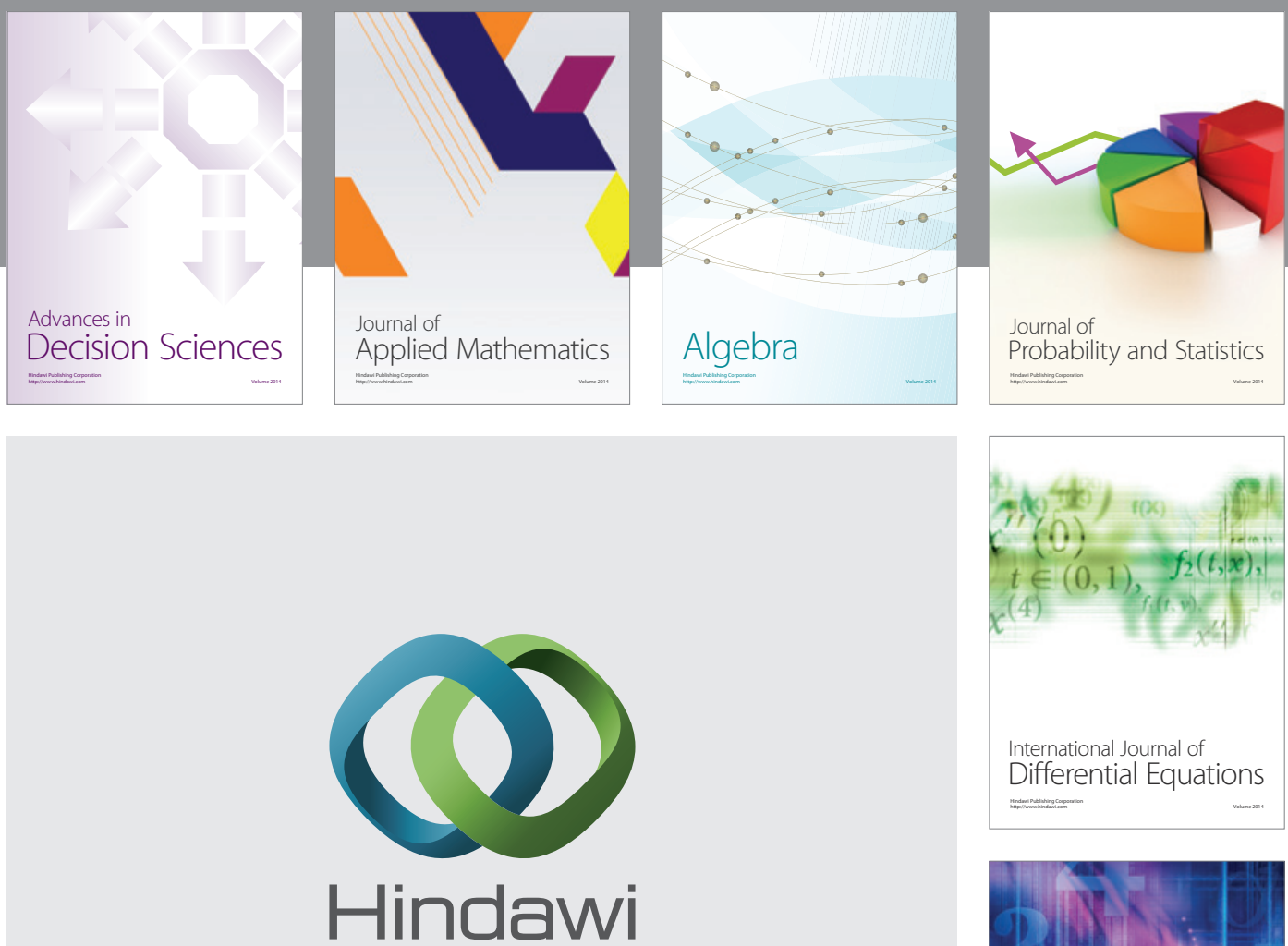

Submit your manuscripts at http://www.hindawi.com
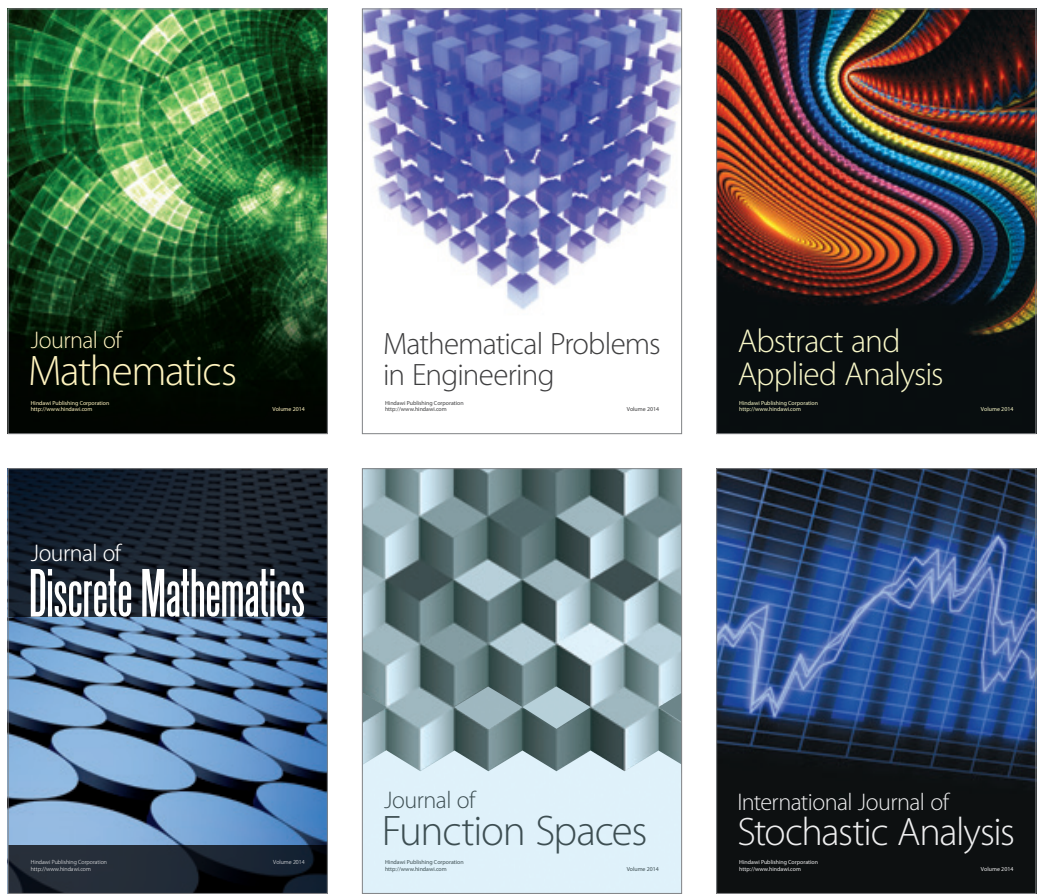

Journal of

Function Spaces

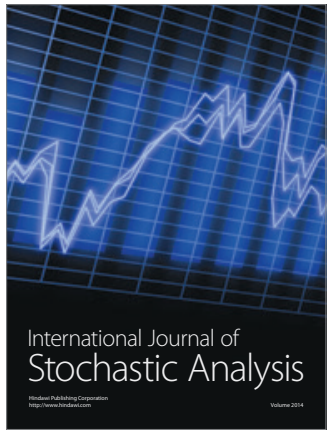

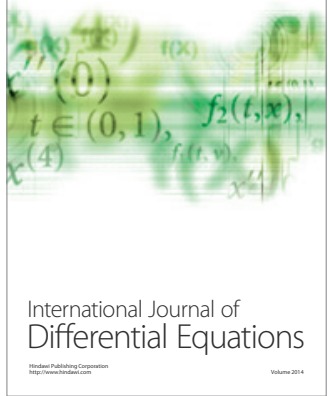
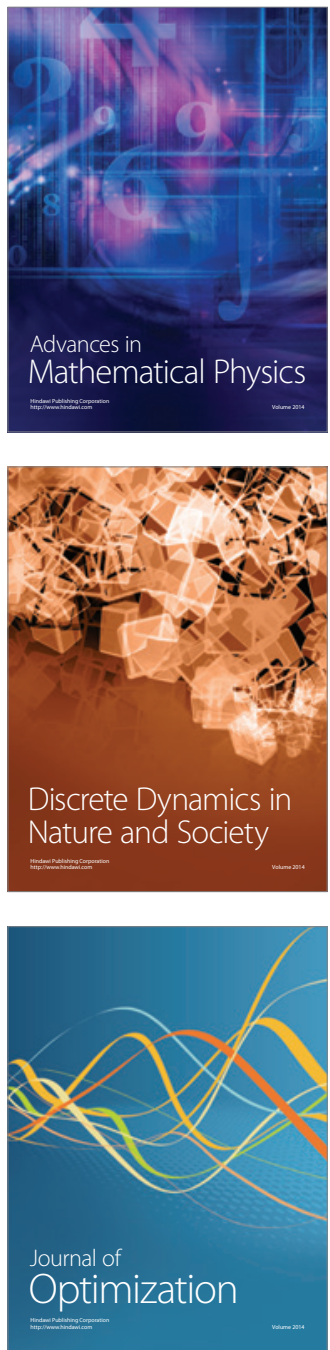